\title{
In vitro spheroid model of placental vasculogenesis: does it work?
}

\author{
Nelli Baal ${ }^{1,2,5}$, Rebecca Widmer-Teske ${ }^{3,5}$, Timothy McKinnon ${ }^{4}$, Klaus T Preissner $^{2}$ and Marek T Zygmunt ${ }^{3}$
}

Placental vascular development begins very early in pregnancy and is characterized by construction of a primitive vascular network in a low-oxygen environment. In vitro three-component assays of this process are scarce. In this study, a complex three-dimensional spheroid model for in vitro studies of placental vasculogenesis with regard to cell-cell interactions between cytotrophoblasts (CTs), villous stromal cells and endothelial precursor cells was established. Microscopic and immunohistochemical analyses of the spheroids showed structural and differentiation patterns resembling the structure and differentiation of early placental chorionic villous tissue (in regard to the expression of multiple markers cytokeratin-7, vimentin, CD34, CD31). The authenticity of this model to in vivo events allowed investigation of placental vascular development and trophoblast invasion under physiological and pathological conditions. Particularly enhanced spheroidal expression of SDF-1 $\alpha$ and its receptor CXCR4, the major chemokine system in embryonic vasculogenesis, in a low-oxygen environment was detected. In addition, our model confirmed previously described invasive phenotype of trophoblasts through collagen under low- (physiologic), but not high- (pathologic) oxygen concentrations. Therefore, the three-dimensional spheroid model consisting of major placental cell types proved to be an appropriate system to investigate early placental vessel development under both physiological and pathological conditions.

Laboratory Investigation (2009) 89, 152-163; doi:10.1038/labinvest.2008.126; published online 15 December 2008

KEYWORDS: placental vasculogenesis; trophoblast; endothelial precursor cells; spheroid model

The establishment of a vascular network is one of the earliest events in embryonic/placental development and essential for fetal growth. ${ }^{1}$ Aberrant vascular development of the placental vascular tree has been linked in a number of serious pregnancy-related complications including intrauterine growth restriction, preeclampsia or early pregnancy loss. ${ }^{2-4}$ As epidemiological studies have revealed a strong correlation between intrauterine growth and retardation and disease mechanisms in later life, placental vascular development is an important determinant of health in adulthood. ${ }^{5}$

Vascularization of the human placenta occurs independently of embryonic vascular development and begins in tertiary chorionic villi composed of an outer trophoblastic layer (syncytiotrophoblasts) and an inner mesenchymal villous core. ${ }^{6-8}$ Syncytiotrophoblasts arise from the fusion of villous cytotrophoblasts (CTs) and have important absorptive and secretory function in the developing placenta. A subset of
CTs aggregate and form columns in anchoring villi. The CTs attach to the superficial portion of the uterus and subsequently invade the walls of the uterine spiral arterioles. Thus, CT invasion anchors the fetus to the mother and participates in the remodeling of maternal uterine vessels. ${ }^{9-11}$ Inner structures of chorionic villi are infiltrated by stromal cells thereby forming an early site for blood vessel development. Interactions of endothelial/hematopoietic progenitor cells with adjacent trophoblast and villous stromal cells (VSCs) are essential for this process as well as development and maintenance of an extensive placental vasculature. As trophoblast is a rich source of angiogenic growth factors affecting hematopoietic progenitor cells, placental vascular development might be influenced by trophoblast. ${ }^{8}$ Furthermore, angiogenic factors of trophoblastic origin seem to have an impact on cell migration, an important process of vascular development. Ang-2, eg, stimulates the migration of

\footnotetext{
Department of Obstetrics and Gynecology, University of Giessen, Giessen, Germany; ${ }^{2}$ Department of Biochemistry, University of Giessen, Giessen, Germany;

${ }^{3}$ Department of Obstetrics and Gynecology, University of Greifswald, Greifswald, Germany and ${ }^{4}$ Center for Stem Cell and Regenerative Medicine, University of Southern California, Los Angeles, CA, USA

Correspondence: Dr MT Zygmunt, MD, PhD, Department of Obstetrics and Gynecology, University of Greifswald, Wollweberstr 1, Greifswald, D-17475 MV, Germany. E-mail: zygmunt@uni-greifswald.de

${ }^{5}$ These authors contributed equally to this work.

Received 2 July 2008; revised 22 September 2008; accepted 27 September 2008
} 
endothelial precursor cells (EPCs). ${ }^{12}$ As early as 21 days p.c., structures within the chorionic villi termed hemangioblastic cords could be detected. ${ }^{13}$ These structures consist of CD34-positive cells called angioblasts. Angioblasts start to cluster and reorganize to form capillary-like structures. ${ }^{14}$ The induction of angioblasts and the assembly of primordial vessels is tightly regulated by a number of cytokines, growth factors like VEGF and FGF, components of the extracellular matrix and its receptors. ${ }^{15}$ The angiopoietins Ang- 1 and Ang2 and their respective receptor Tie2 are responsible for a balance between stabilization and remodeling of the primary capillary plexus and for survival of endothelial cells. ${ }^{16-18}$ These factors have been detected in early chorionic villi, as well. ${ }^{19}$ Recently, placenta has also been shown to be a rich source of the cytokine SDF-1 $\alpha /$ CXCL12 and its receptor CXCR $4{ }^{20,21}$ As regulatory processes of early placental vascular development occur in an low-oxygen environment, we recently investigated the function of the placental-derived SDF-1 $\alpha / C X C R 4$ system under physiologically relevant oxygen tensions. $^{22,23}$ We have demonstrated that SDF- $1 \alpha$ recruits human stem/progenitor cells to sites of placental vascular development.

Owing to the unique structure of the human placenta, available functional assays of vascularization are sparse, whereas the precise mechanisms of early placental vascularization remain unclear. ${ }^{24}$ As endothelial progenitor cells of placental origin may contribute to different vascular pathologies in postnatal life (eg infantile hemangioma), there is a strong need to establish adequate models of placental vasculogenesis. $^{25}$

In this study, a complex three-dimensional, threecomponent coculture model of developing vessels in the human placenta was successfully established and utilized for in vitro placental vasculogenesis- and trophoblast invasion studies in physiological relevant oxygen environment.

\section{MATERIALS AND METHODS}

\section{Cell Isolation and Cultivation}

First trimester cytotrophoblast and villous stromal cell cultures

Magnetic-activated cell sorting (MACS; Miltenyi Biotech, Bergisch Gladbach, Germany) was applied isolate CTs from early placental tissue collected from elective abortions after written consent from the patients and approval by the Ethics Committees (JLU, Giessen, Germany, and EMAU, Greifswald, Germany) was obtained. Enzymatic digestion of minced chorionic villi fragments was conducted as described previously. ${ }^{26}$ Cells were subsequently separated using an antibody against CD326 (Miltenyi Biotech), an epithelial cell adhesion molecule expressed by CTs. Up to $90 \%$ of the $\mathrm{CD}^{2} 6^{+}$cells also expressed specifically cytokeratin-7 as proven by flow cytometry. CTs were then expanded in Amniomax serum-free medium containing commercially available supplements (Gibco, Karlsruhe, Germany). Cells from the unlabeled CD326-negative cellular fraction, referred to as VSCs, were also collected. VSCs were grown in DMEM
(Gibco) containing 10\% FCS (Gibco) and identified by flow cytometry using vimentin, a mesenchymal marker. CT and VSC cultures were typically used at passage 5 .

\section{$\mathrm{CD}_{133^{+}}$cells (endothelial precursor cells) from human umbilical cord blood}

Human umbilical cord blood (UCB) was collected from term pregnancies following caesarean section as previously described. ${ }^{27}$ Briefly, the blood was diluted with PBS supplemented with $2 \mathrm{mM}$ EDTA and subjected to density gradient centrifugation using Ficoll-Pacque $(1.077 \mathrm{~g} / \mathrm{ml}$; Amersham Biosciences, Uppsala, Sweden). The mononuclear cell fraction was removed and CD133-expressing cells were isolated by using MACS employing an antibody against CD133. Owing to the coexpression of CD34, CD31 and CD133 antigens, these cells are also referred to as EPCs. EPC cultures were expanded in IMDM (Gibco) containing 10\% FCS, $10 \mathrm{ng} / \mathrm{ml}$ stem cell factor, $20 \mathrm{ng} / \mathrm{ml}$ thrombopoietin and $50 \mathrm{ng} / \mathrm{ml} \mathrm{Flt-3-Ligand} \mathrm{(all} \mathrm{growth} \mathrm{factors} \mathrm{from} \mathrm{Promokine,}$ Heidelberg, Germany) for 7 days before the experiments were started. Medium was replaced every 3-4 days.

\section{Human umbilical vein endothelial cells}

Human umbilical vein endothelial cells (HUVEC) were isolated based on established methods described by Jaffe et $a l^{28}$ with minor alterations. In brief, the cord was rinsed with HBSS and filled with collagenase solution consisting of HBSS (Gibco) with $\mathrm{Mg}^{2+} / \mathrm{Ca}^{2+}$ and $200-265 \mathrm{U} / \mathrm{ml}$ collagenase IV (Biochrom, Berlin, Germany). Both cord endings were pinched with forceps and the cord was incubated at $37^{\circ} \mathrm{C}$ for $20 \mathrm{~min}$. The collagenase solution was collected, the vein washed with HBSS and digested endothelial cells were centrifuged at 1500 r.p.m. for $10 \mathrm{~min}$. HUVECs were cultured in EBM-MV2 medium with supplied growth factors (PromoCell, Heidelberg, Germany) used up to passage 7 .

\section{Human placental trophoblast-conditioned medium}

Conditioned media was produced by incubation of subconfluent CTs in IMDM without supplements for $12 \mathrm{~h}$. Media were removed, centrifuged at 4000 r.p.m. for $10 \mathrm{~min}$ and stored at $-80^{\circ} \mathrm{C}$ until required.

\section{Formation of spheroids}

For the investigation of cell-cell interactions between the isolated cellular components in vasculogenesis, a threedimensional spheroid model was developed. To generate spheroids of defined size and cell number, $5 \times 10^{2} \mathrm{EPCs}$, $1.5 \times 10^{3}$ CTs and $1.5 \times 10^{3}$ VSCs (ratio 1:3:3) per spheroid were mixed and resuspended in cell culture medium containing AmnioMax ${ }^{\mathrm{TM}}-100$ (containing the appropriate commercially available supplements) and IMDM medium (ratio 1:1) supplemented with $0.25 \%(\mathrm{w} / \mathrm{v})$ methyl cellulose and $1 \%$ FCS. The cell suspension was cultured in a 96-well plate (100 $\mu \mathrm{l}$ per well; Cellstar, Greiner Bio-One, 
Frickenhausen, Germany) at $37^{\circ} \mathrm{C}$ in physiologically relevant oxygen concentrations as described below. Spheroid formation was observed within 18-20 h. Where applicable, EPCs and VSCs were labeled with a PKH-26 Kit (red) and a PKH2 Kit (green), respectively, as described by the manufacturer (Sigma, Munich, Germany). CTs remained unlabeled.

\section{Spheroid Formation in Physiological Oxygen Environments}

Spheroid formation was investigated in environments containing low oxygen thereby mimicking physiologically relevant oxygen concentrations as described previously and recently applied in our laboratory. ${ }^{22,23}$ In brief, cells were prepared for spheroid formation as described above and incubated in Modular Incubator Chambers (BillupsRothenburg, Del Mar, CA, USA) for $24 \mathrm{~h}$. The chambers were flushed with appropriate gas mixtures for $4 \mathrm{~min}$ at a rate of approximately $25 \mathrm{l} / \mathrm{min}$ three times a day. The gas mixtures used in this study consisted of either 1 or $8 \% \mathrm{O}_{2}$. The modular incubator chambers were placed in a $37^{\circ} \mathrm{C}$ incubator during the course of the experiment. As a control, spheroids were cultivated in $21 \% \mathrm{O}_{2}$.

\section{In vitro invasion assay}

The in vitro invasion assay was conducted similarly to the recently described assays with minor modifications..$^{29,30}$ Spheroids were harvested, centrifuged at 1200 r.p.m., $4^{\circ} \mathrm{C}$ for $5 \mathrm{~min}$ and washed with PBS. Thereafter they were resuspended in $4 \mathrm{ml} 1.2 \%(\mathrm{w} / \mathrm{v})$ methyl cellulose in IMDM medium containing $1 \%$ FCS. A volume of $4 \mathrm{ml}$ collagen $(0.35 \mathrm{mg} / \mathrm{ml}$ collagen prepared from rat tails in $0.1 \%$ acetic acid) was supplemented with $400 \mu \mathrm{l} 10 \times 199$-medium (Gibco) and neutralized with $500 \mu \mathrm{l} 0.2 \mathrm{M} \mathrm{NaOH}$. The $\mathrm{pH}$ value was adjusted to 7.4. The spheroids were mixed with collagen and equally distributed on a 24 -well plate. The polymerization took place within $30 \mathrm{~min}$ at $37^{\circ} \mathrm{C}$. Invasion was recorded under appropriate $\mathrm{O}_{2}$ concentration using a live cell imaging system including a fluorescence microscope (Nikon TE2000; Nikon, Duesseldorf, Germany). Images were obtained every $15 \mathrm{~min}$ utilizing phase contrast, FITC and RhodRedX filters. Following a $24 \mathrm{~h}$ incubation period, live recording documentation of the experiments was generated using NIS Elements AR (version 2.3) software (Nikon).

\section{Spheroid fixation and characterization}

Spheroids were collected, fixed with $4 \%$ paraformaldehyde for $15 \mathrm{~min}$, washed with PBS and resuspended in $100 \mu \mathrm{l}$ collagen $(0.35 \mathrm{mg} / \mathrm{ml}$ collagen in $0.1 \%$ acetic acid) for the embedding in Tissue-Tek ${ }^{\mathbb{R}}$. Storage at $-80^{\circ} \mathrm{C}$ and cryoslicing $(8 \mu \mathrm{m})$ followed. The spheroids were transferred onto a thin layer of frozen TissueTek ${ }^{\circledR}$, then overlaid with TissueTek ${ }^{\circledR}$ and stored at $-80^{\circ} \mathrm{C}$. Cryoslices were transferred to SuperFrost Ultra Plus object holders (Gerhard Menzel Glasbearbeitungswerk GmbH \& Co. KG, Braunschweig, Germany) and subjected to immunostaining as described below.

\section{Immunocytochemistry}

Cultures were centrifuged, washed with PBS and fixed in Zamboni solution containing paraformaldehyde and picric acid for $15 \mathrm{~min}$ at room temperature. Cells were washed in PBS overnight at $4^{\circ} \mathrm{C}$ and subsequently transferred to a SuperFrost Ultra Plus object holder to a final concentration of $1 \times 10^{6}$ per $10 \mu \mathrm{l}$ and dried for $24 \mathrm{~h}$. Fixed cells were washed in PBS, blocked with $10 \%$ donkey serum (PBS; $1 \%$ BSA, $0.1 \%$ Triton X-100) for $1 \mathrm{~h}$ and incubated with a primary antibody diluted in PBS supplemented with $1 \%$ donkey serum and $0.1 \%$ Triton X-100 for $1 \mathrm{~h}$. Anti-CD68 (1:300) (BD, Heidelberg, Germany) and anti-VEGFR-3 (1:10) (R\&D Wiesbaden-Nordenstadt, Germany) were used as primary antibodies. Thereafter, cells were washed, incubated in a 1:1000 dilution of Rhodamine Red-conjugated donkey antimouse IgG (Jackson ImmunoResearch) for $1 \mathrm{~h}$ and washed again. Nuclei were counterstained for $5 \mathrm{~min}$ with $5 \mu \mathrm{g} / \mathrm{ml}$ Hoechst 33342 (Merck Biosciences, Darmstadt, Germany). SuperFrost Ultra Plus object holders (Gerhard Menzel Glasbearbeitungswerk $\mathrm{GmbH}$ \& Co.KG) were mounted with ProLong ${ }^{\mathbb{R}}$ Gold (Invitrogen, Karlsruhe, Germany). Fluorescent cells were visualized with a fluorescence microscope (Nikon TE2000; Nikon) and images captured using NIS Elements AR version 2.3 software (Nikon).

Immunohistochemistry of early placental tissue and spheroids Early placental tissue $(5 \times 5 \times 5 \mathrm{~mm}$ pieces $)$ and spheroids were collected, fixed with $\mathrm{HOPE}^{\circledR}$-Fixation (DCS, Hamburg, Germany) and paraformaldehyde (4\%), respectively, embedded in Tissue-Tek ${ }^{\circledR}$ OTC (Sakura Finetek Europe, Zoeterwoude, Holland) and immediately immersed in liquid nitrogen. Frozen blocks were stored at $-80^{\circ} \mathrm{C}$ until cryoslicing $(8 \mu \mathrm{m})$. Slices were blocked as described above and incubated with a primary antibody overnight at $4^{\circ} \mathrm{C}$. Antibodies used were anti-cytokeratin-7 (1:40) (Dako, Hamburg, Germany), anti-vimentin (1:100) (Santa Cruz, Heidelberg, Germany), anti-CD31 (1:50) (Dako), anti-SDF1- $\alpha$ (Santa Cruz) (1:50), anti-CXCR4 (1:100) and anti-CD34 (1:100) (Immunotech, Hamburg, Germany). The secondary Alexa 488- or Alexa 555-conjugated antibody (1:1500) (BD) was applied and nuclei were stained as mentioned above. ProLong ${ }^{\circledR}$ Gold (Invitrogen) mounting and visualization with the fluorescence confocal microscope followed.

\section{Tube formation assay}

The ability of endothelial cells to form tubes or networks was tested as previously described. ${ }^{22}$ In brief, growth factorreduced Matrigel $^{\mathrm{TM}}$ was diluted 1:2 with cold IMDM without supplements and pipetted in volumes of $50 \mu \mathrm{l}$ per well in a 96-well plate $\left(150-200 \mu \mathrm{l}\right.$ per $\left.1 \mathrm{~cm}^{2}\right)$ and polymerized $1-2 \mathrm{~h}$ at $37^{\circ} \mathrm{C}$. Subsequently, $1 \times 10^{4}$ HUVEC- and $1 \times 10^{4} \mathrm{PKH}-26-$ labeled EPCs were mixed, then transferred to the matrix where capillary net structures formed within $20 \mathrm{~h}$. Net structures were visualized with a fluorescence microscope (Nikon) and images captured using NIS Elements AR version 2.3 software (Nikon). 

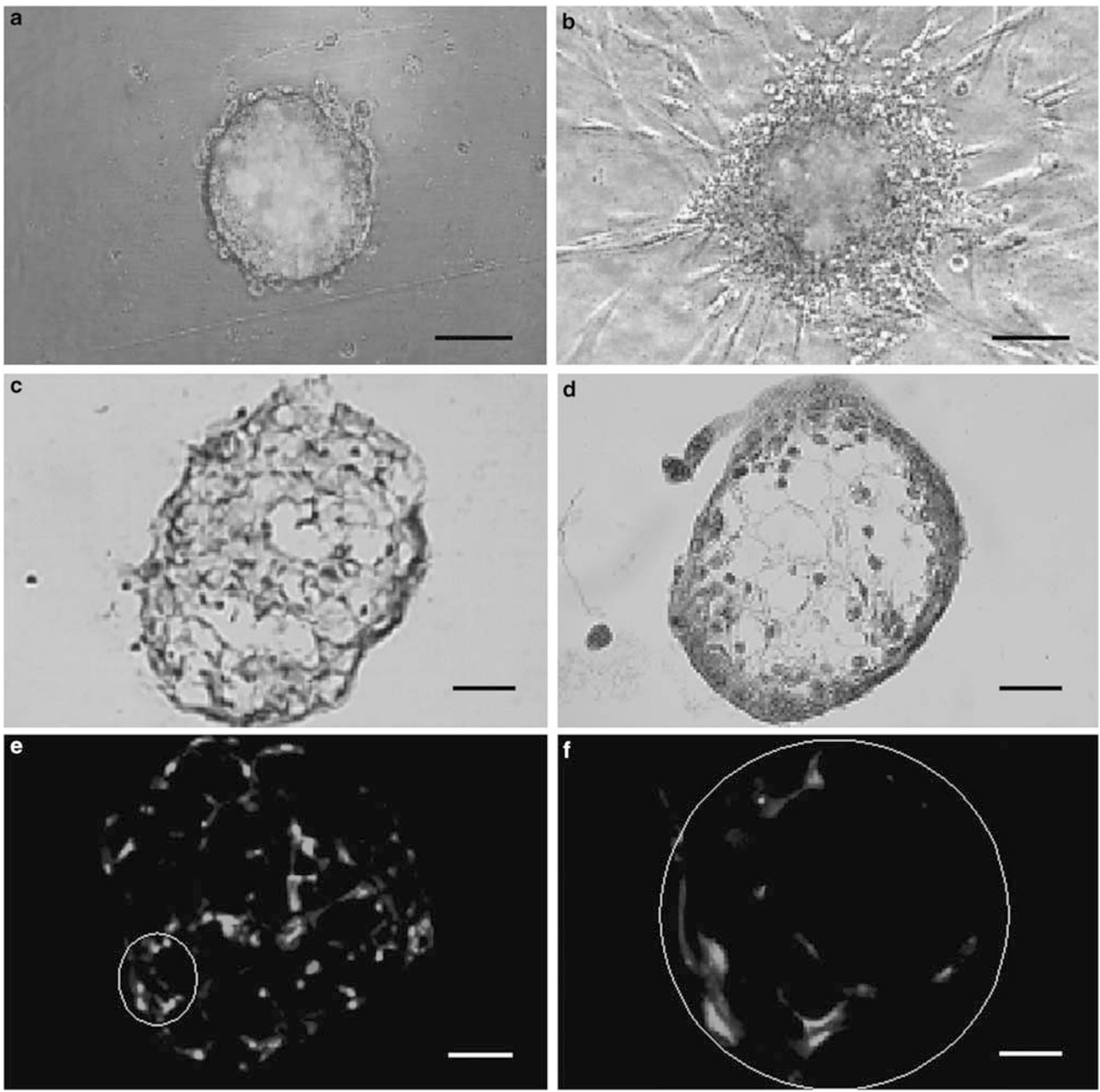

Figure 1 A three-dimensional spheroid composed by EPCS, VSCs and CT. (a) EPCs and VSCs were fluorescently labeled (red and green, respectively) and subsequently cocultured with unlabeled CTs. After approximately $20 \mathrm{~h}$, spontaneous formation of spheroids could be observed. Bar $150 \mu \mathrm{m}$. (b) The spheroids were embedded in a gel-like collagen matrix and incubated for $24 \mathrm{~h}$. CTs leaving the spheroidal core show the invasive phenotype. Bar $150 \mu \mathrm{m}$. (c) The spheroids were collected, fixed with PFA and embedded in a collagen matrix which was cryoconserved in Tissue-Tek ${ }^{\mathbb{R}}$ before cryoslicing (8 $\mu$ m). Slices were subjected to hematoxylin and eosin staining, and the inner structure could be identified as a network formed by CTs, VSCs and EPCs. Bar $50 \mu \mathrm{m}$. (d) Early placental villi were also cryoconserved in Tissue-Tek ${ }^{\mathbb{R}}$ and hematoxylin and eosin stained following cryoslicing $(8 \mu \mathrm{m})$. The cross-sections of the spheroid and placental villi show similar structures. Bar $50 \mu \mathrm{m}$. (e, f) PKH staining of EPCs (red) and CTs (green) within a spheroid. Bars 50 and $10 \mu \mathrm{m}$, respectively.

\section{RESULTS}

\section{Spheroid Development and Characterization}

Following set up of the coculture system, spheroid formation was accomplished in approximately $18 \mathrm{~h}$ and resulted in an average diameter of $200 \mu \mathrm{m}$ per spheroid (Figure 1a). Cross- sections of H\&E-stained spheroids (Figure 1c) and early placental villi (Figure 1d) revealed significant structural similarities between both systems. Further characterization of spheroids was accomplished by fluorescencemicroscopic analysis of cross-sections (Figure 1e and f). 

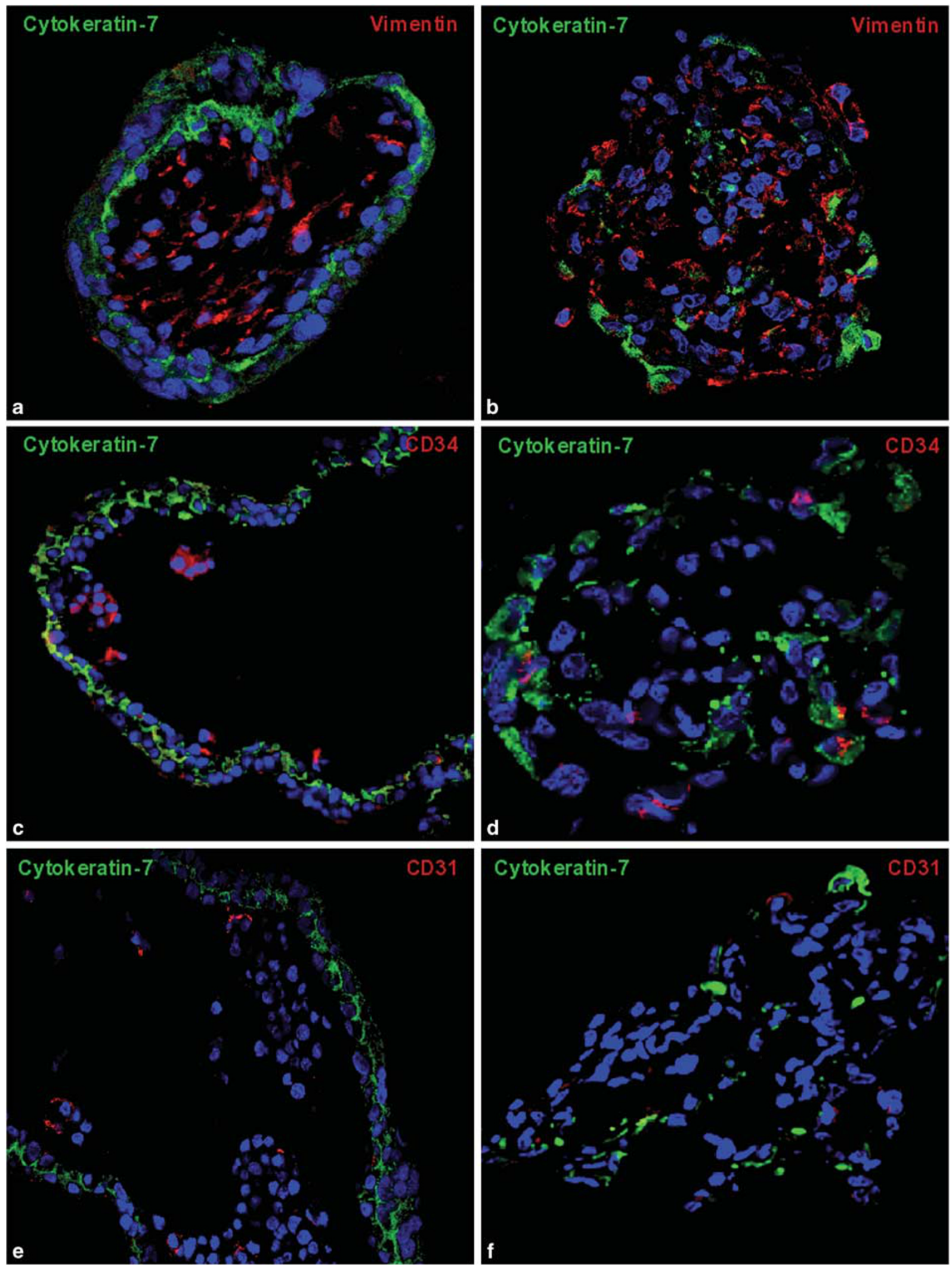

Figure 2 Immunohistochemical analysis of human placental villous tissue and spheroids. (a-f) Differentiation patterns of spheroids comprising CTs, VSCs and EPCs correlate to tissues from early placenta (7 w.p.c.) as shown by immunohistochemical staining. (a, b) CTs were labeled with anti-cytokeratin-7 (green), VSCs with vimentin antibodies (red). (c, d) CD34 expressed on EPCs stained with human anti-CD34 (red). (e, f) CD31 expressed on EPCs stained with human anti-CD31 (red). Cell nuclei were stained with Hoechst (Blue). 


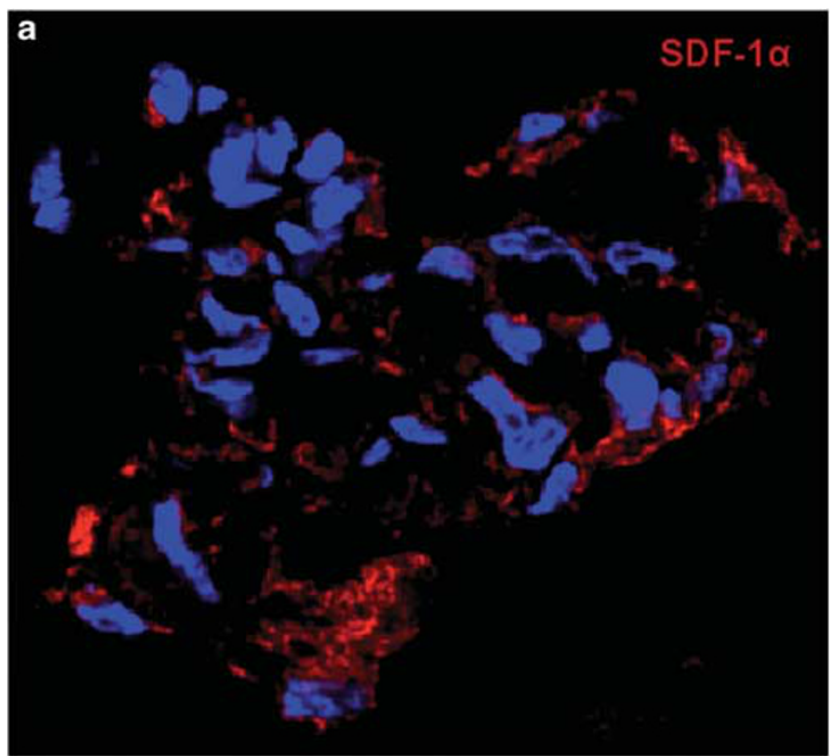

$1 \% \mathrm{O}_{2}$

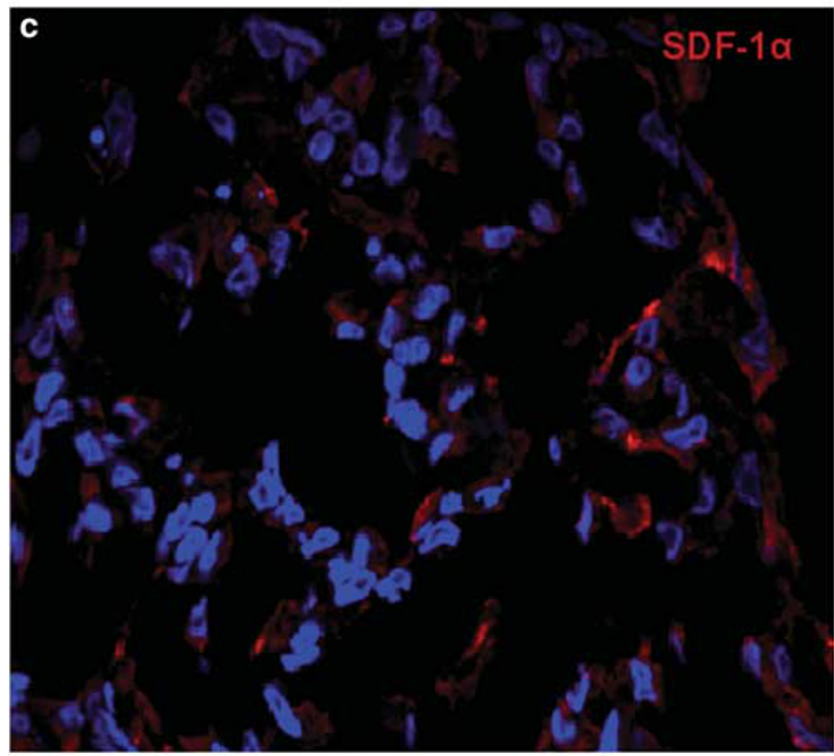

$21 \% \mathrm{O}_{2}$

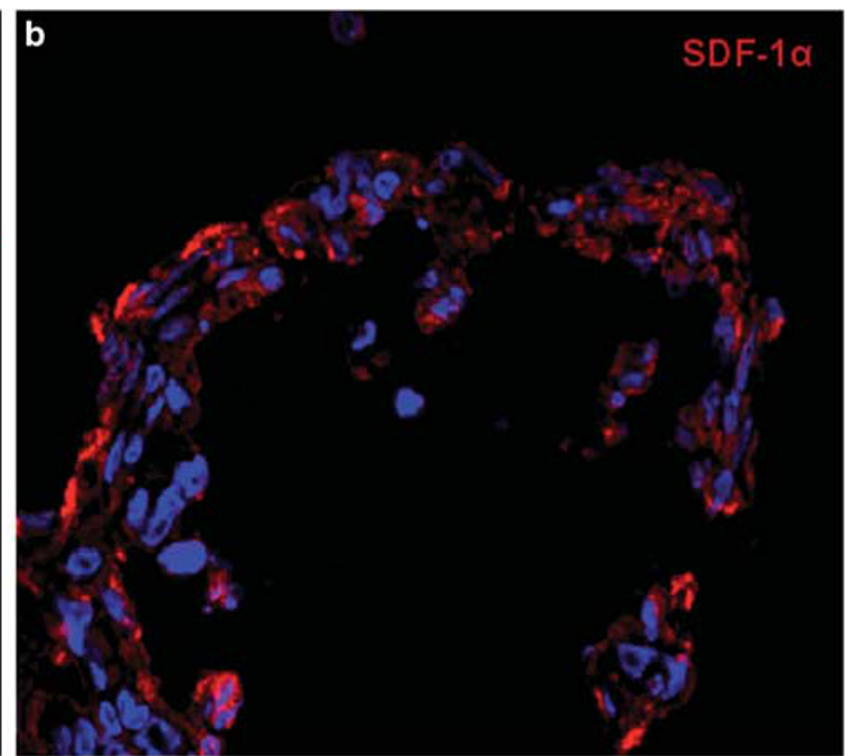

$8 \% \mathrm{O}_{2}$

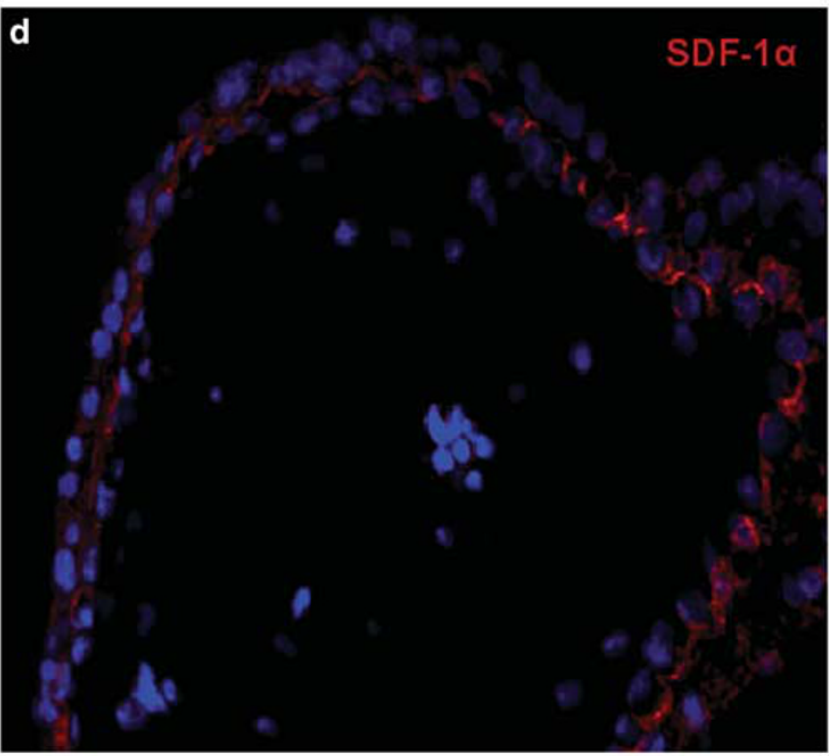

Early placenta (7wpc)

Figure 3 Spheroids show enhanced expression of SDF-1 $\alpha$ in a hypoxic environment. Immunohistochemistry was utilized to examine spheroidal SDF-1 $\alpha$ protein expression in (a) $1 \% \mathrm{O}_{2}$, (b) $8 \% \mathrm{O}_{2}$, (c) $21 \% \mathrm{O}_{2}$ and (d) in human placental tissue from 7 w.p.c.. Tissues were immunolabeled with anti-human SDF- $1 \alpha$ (red) and nuclei stained with Hoechst (Blue).

Spheroids were prepared for in vitro invasion assays, by embedding in a collagen matrix followed by incubation for $24 \mathrm{~h}$. CTs could be observed invading radially out of the spheroid outer layer into the collagen matrix (Figure 1b).

Subsequent immunhistochemical analysis of sections from early placental villi (Figure 2, left panels) and spheroids (Figure 2, right panels), respectively, were performed. Tissues and spheroids were probed with specific fluorochromecoupled antibodies against human cytokeratin-7, vimentin, CD34 and CD31. Cell nuclei were counterstained with
Hoechst (Blue). Remarkable similarities between placental villi and spheroids are shown in Figure 2a-f. Cytokeratin7-expressing CT were organized in a characteristically fashion around the villous core. Vimentin-expressing cells were located in the center of the spheroid and the villus from early placenta (Figure 2a and b). A significant number of hematopoietic and EPCs $\left(\mathrm{CD} 34^{+}\right.$cells) were detected within the spheroidal core and the villous stroma (Figure $2 c$ and $d$ ). Differentiated endothelial cells $\left(\mathrm{CD} 31^{+}\right)$were faintly detected in focal areas of the spheroid and villous tissue (Figure 2e and $\mathrm{f}$ ). 


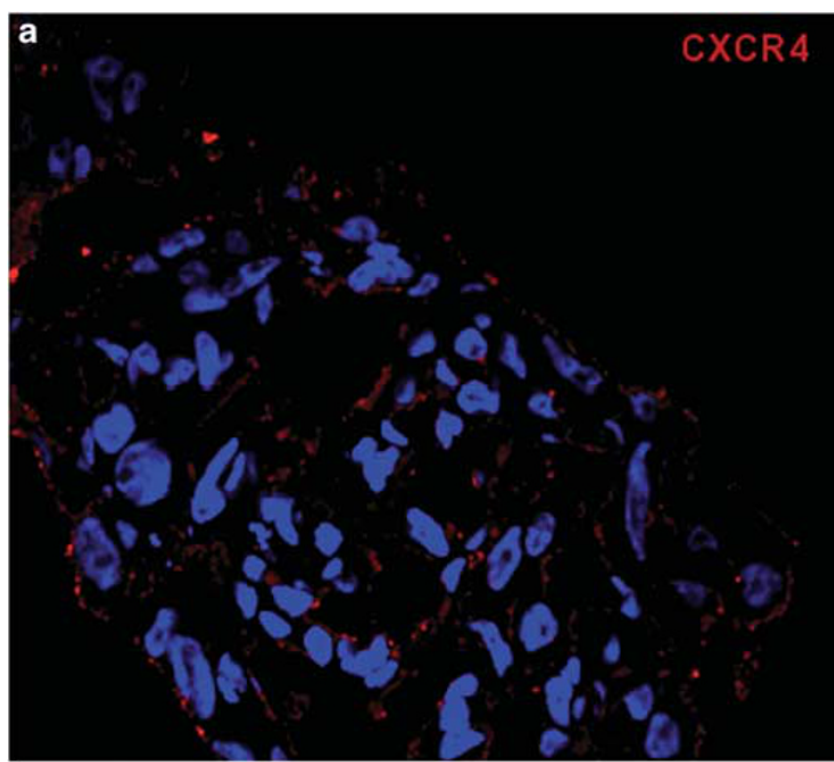

$1 \% \mathrm{O}_{2}$

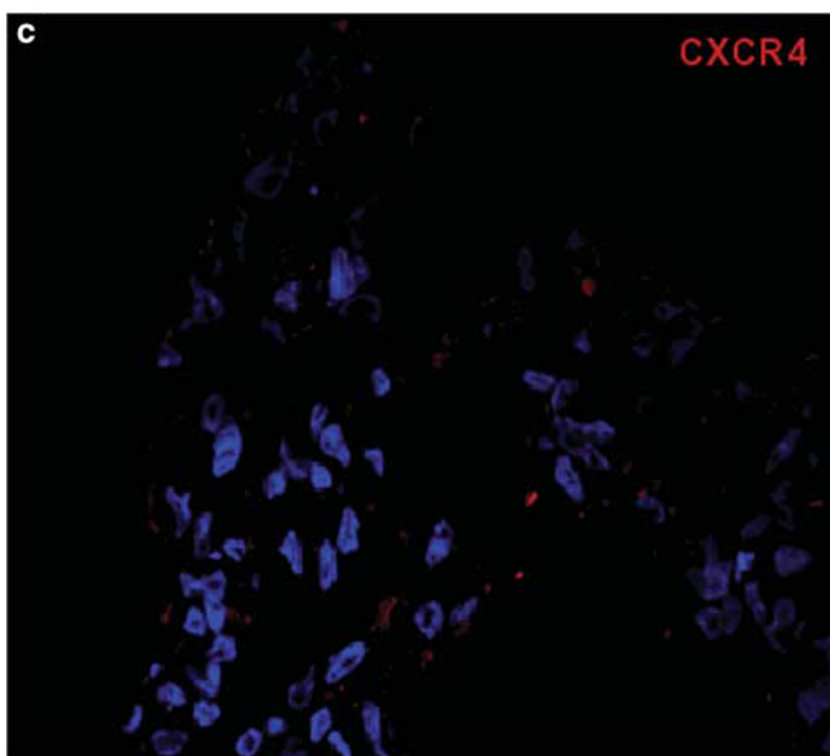

$21 \% \mathrm{O}_{2}$

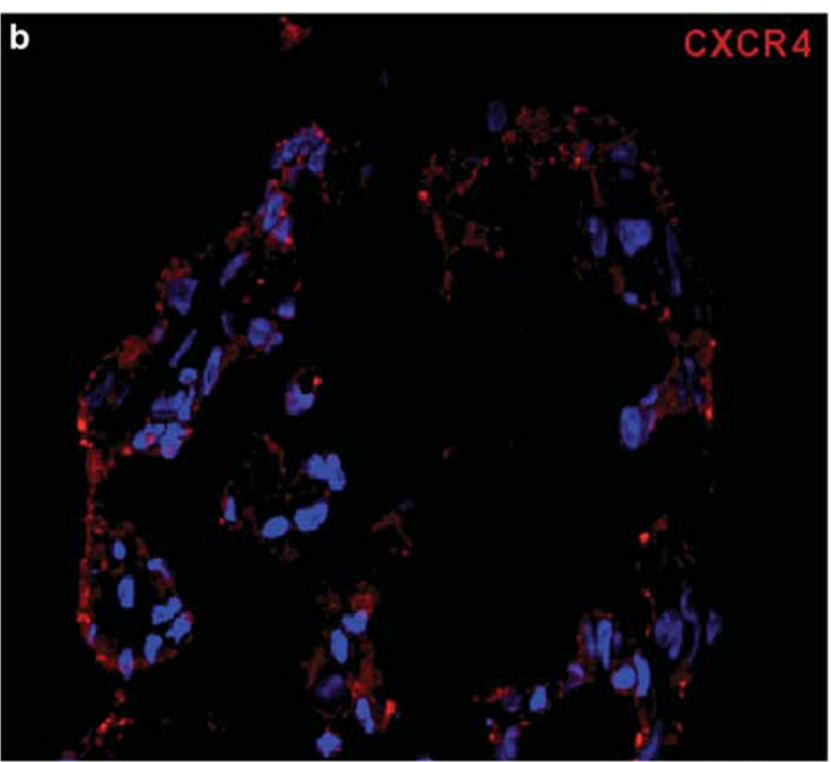

$8 \% \mathrm{O}_{2}$

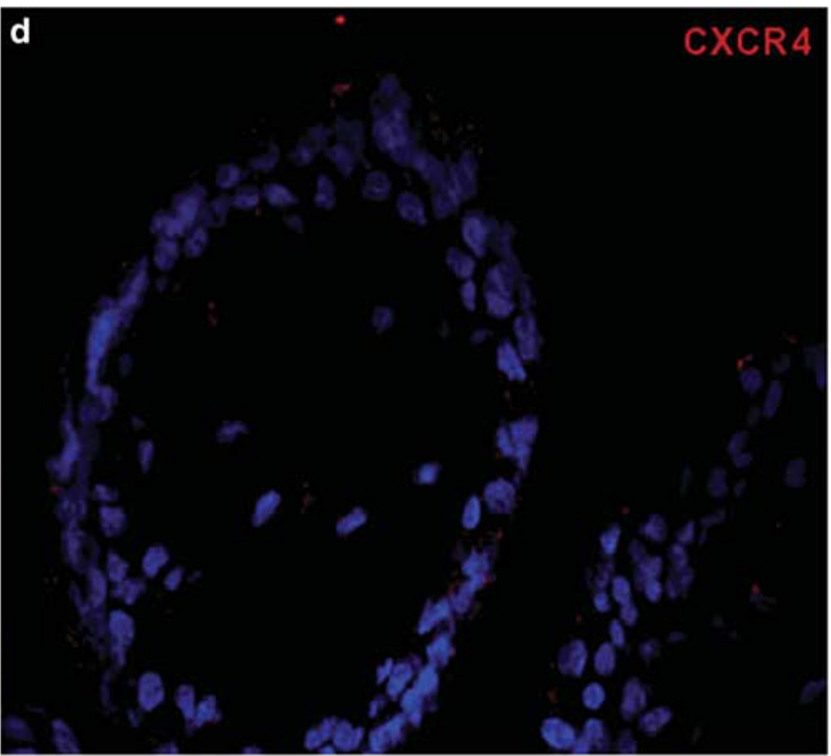

Early placenta (7wpc)

Figure 4 Spheroids show enhanced expression of CXCR4 in a hypoxic environment. Immunohistochemistry was utilized to examine spheroidal CXCR4 protein expression in (a) $1 \% \mathrm{O}_{2}$ (b) $8 \% \mathrm{O}_{2}$, (c) $21 \% \mathrm{O}_{2}$ and (d) in human placental tissue from 7 w.p.c. Tissues and speroids were immunolabeled with antihuman SDF- $1 \alpha$ (red) and nuclei stained with Hoechst (Blue).

\section{Enhanced SDF-1 $\alpha$ - and CXCR4 Expression in Spheroids Under Low Oxygen}

Immunohistochemistry was employed to test the expression of SDF- $1 \alpha$ and the corresponding receptor CXCR4 following $24 \mathrm{~h}$ incubation of spheroids under hyperoxic (21\%) and hypoxic ( 8 and $1 \%$ ) conditions. When spheroids were incubated in $8 \%$ $\mathrm{O}_{2}$, a mean $\mathrm{pO}_{2}$ of $65.0 \pm 7.5 \mathrm{~mm} \mathrm{Hg}$ was maintained. This environmental condition is similar to the oxygen tension found in placental beds from pregnancies at $10-15$ w.p.c. $(65.0 \pm 3.4 \mathrm{~mm} \mathrm{Hg}) .{ }^{31}$ When spheroids were incubated in $1 \%$ $\mathrm{O}_{2}$, the mean $\mathrm{pO}_{2}$ measured was $10.2 \pm 5.5 \mathrm{~mm} \mathrm{Hg}$. These oxygen tensions were similar to previously described physiological $\mathrm{pO} 2$ in the placenta at $8-10$ w.p.c. $(17.9 \pm 6.9 \mathrm{~mm} \mathrm{Hg}){ }^{23}$ SDF- $1 \alpha$ - and CXCR4 immunoreactivity was detected in early tissue as well as in spheroids (Figure 3 ). If cultured in low-oxygen concentrations ( 1 and $\left.8 \% \mathrm{O}_{2}\right)$, enhanced SDF- $1 \alpha$ expression in spheroids was noted (Figure 3a and b) as compared to $21 \% \mathrm{O}_{2}$ (Figure $3 \mathrm{c}$ and d). In Figure 4, CXCR4 immunoreactivity in low oxygen and hyperoxic environments is illustrated, whereby CXCR4 expression in lowoxygen concentrations is enhanced (Figure $4 \mathrm{a}$ and $\mathrm{b}$ ) as compared to $21 \% \mathrm{O}_{2}$ (Figure $4 \mathrm{c}$ and $\mathrm{d}$ ). 


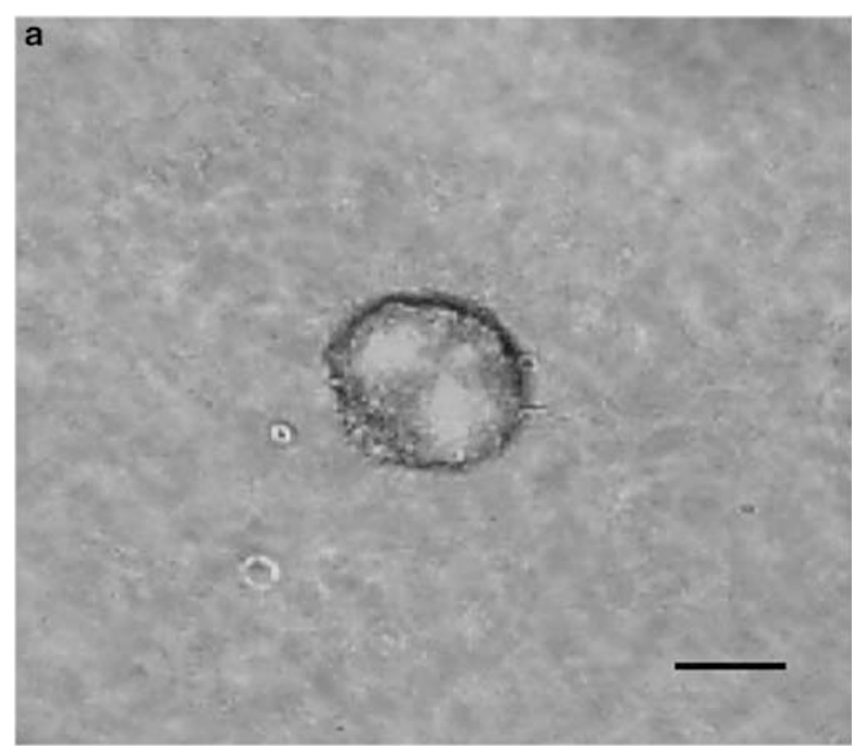

$\mathbf{O h}$

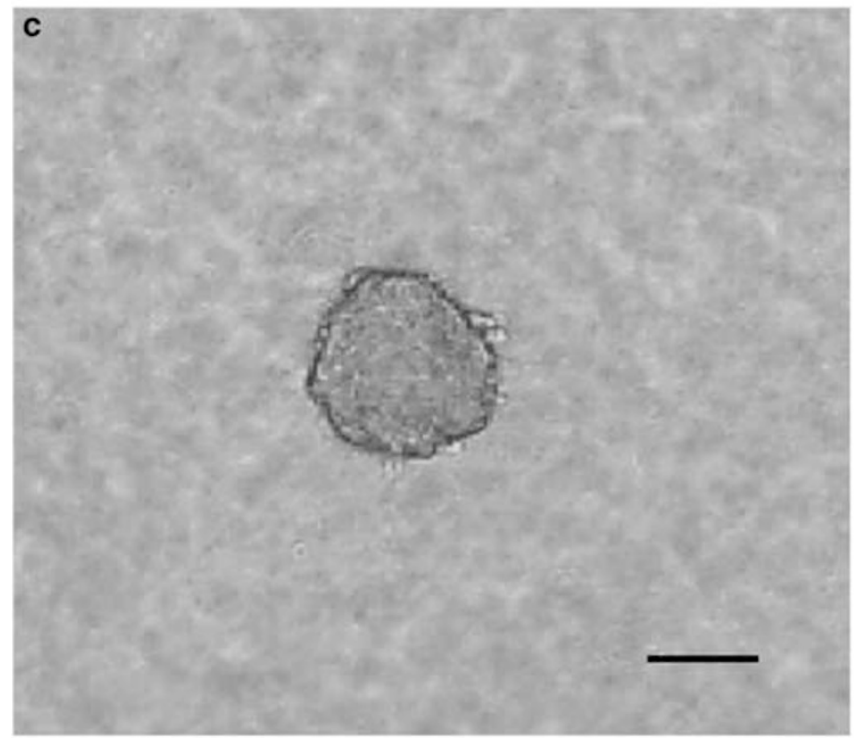

$\mathbf{O h}$

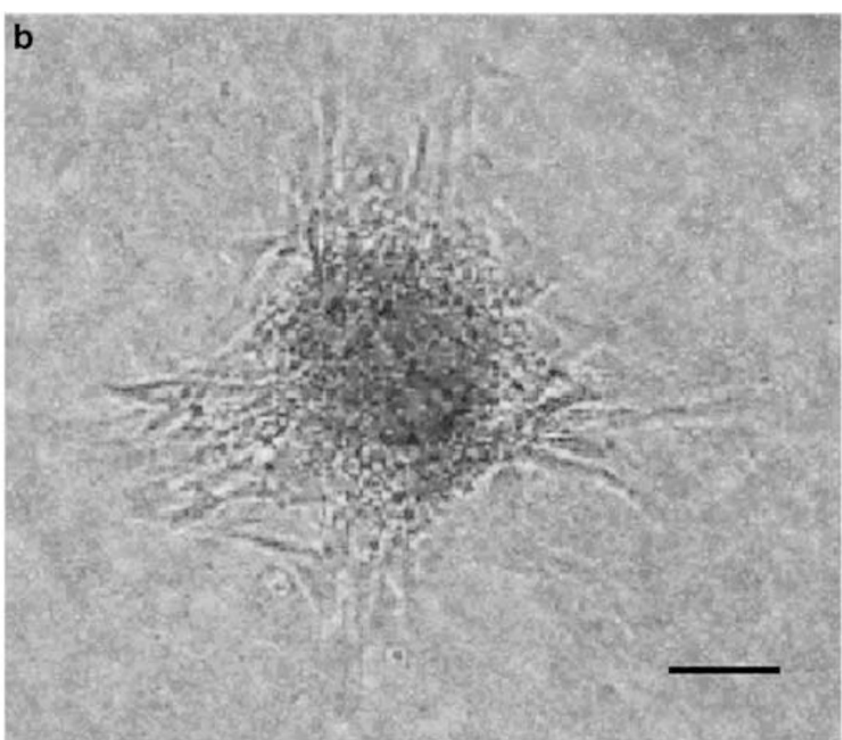

$24 \mathrm{~h}$

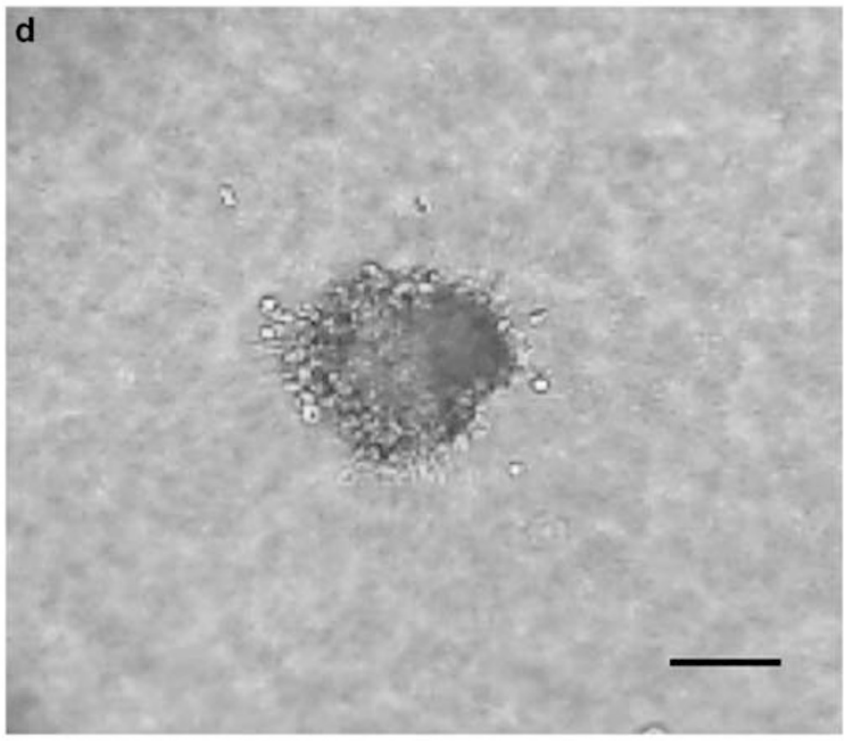

$24 \mathrm{~h}$

Figure 5 Hypoxia-induced CT invasion. (a, b) Invasion into a collagen matrix induced by incubation in a physiologically low-oxygen environment (1\% $\mathrm{O}_{2}$ ) during the course of the experiment $(24 \mathrm{~h})$. (c, d) Incubation in atmospheric oxygen $\left(21 \% \mathrm{O}_{2}\right)$ showed reduced invasion. Bars $150 \mu \mathrm{m}$.

\section{CT Invasion in Physiologically Relevant Oxygen Tensions}

To study CT invasion out of the spheroids, an in vitro invasion assay during additional $24 \mathrm{~h}$ incubation under appropriate oxygen concentrations was applied. During the course of the experiment, in vitro invasion was monitored using a live cell imaging system. CT invaded into the collagen matrix under the hypoxic environment (Figure 5a and b; Supplementary Video 1) which only scarcely proceeded under $21 \% \mathrm{O}_{2}$ (Figure $5 \mathrm{c}$ and $\mathrm{d}$; Supplementary Video 2).

\section{DISCUSSION}

In previously published in vitro studies of placental vascular development, different types of placental cells formed a two-dimensional mononuclear layer supposedly mimicking many of the phenotypic and functional properties in the villous tissue. ${ }^{24,32}$ Unfortunately, these two-dimensional cell culture systems have significant limitations as cells may lose their functional and differentiated phenotypic properties. For example, endothelial cell differentiation antigens such as CD34 are downregulated after transfer into two-dimensional culture system, and other endothelial cells lose their 

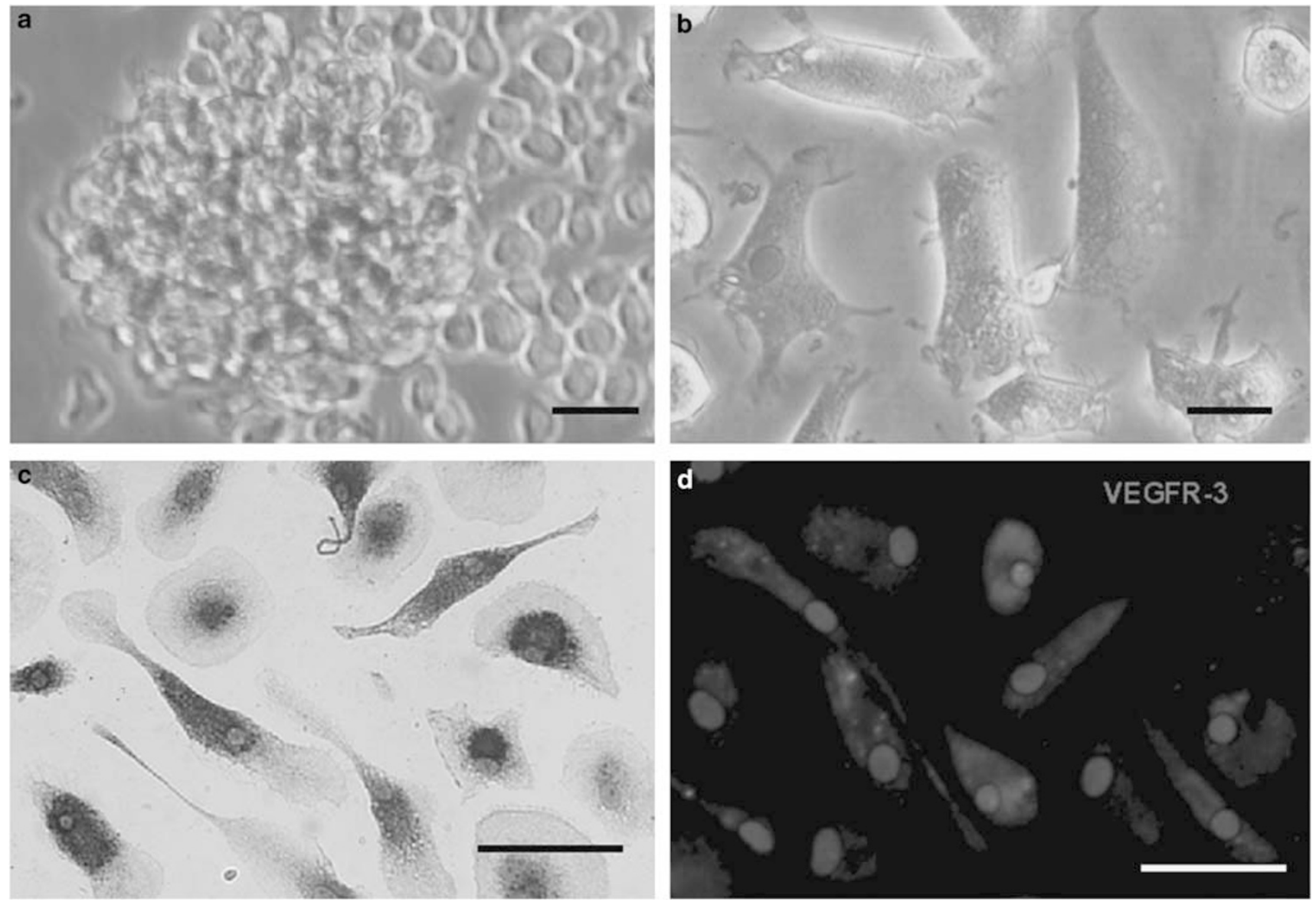

Figure 6 Morphology of long-term-cultured EPCs in HTR-CM. EPCs were cultured in HTR-CM supplemented with 1\% FCS. (a) After 4 weeks incubation, cells formed spheroids that did not attach to the bottom of the culture flask. Bar $20 \mu \mathrm{m}$. (b) After following $24 \mathrm{~h}$ incubation in IMDM medium supplemented with $1 \%$ FCS, cells became adhesive and showed an endothelial-like morphology (bar $20 \mu \mathrm{m}$ ), expressed macrophagial CD68 (c) and VEGFR-3 (d) after $24 \mathrm{~h}$ incubation in IMDM medium supplemented with 1\% FCS following 4-week incubation in HTR-CM. Nuclei are counterstained with Hoechst (Blue). Bars $50 \mu \mathrm{m}$.

tight junction-dependent characteristics in two-dimensional culture. $^{33,34}$

Instead of two-dimensional cell culture systems, spheroid models of tumor- and embryonic stem cells have been extensively employed to investigate cellular differentiation, cell-cell interactions, cellular hypoxia responses as well as in therapeutically oriented studies. ${ }^{35-39}$ Recently established three-dimensional endothelial spheroid models of vascular differentiation have shown a positive influence on cellular apoptosis, cell-cell signaling and expression of vasoactive cytokines and growth factors. ${ }^{40-43}$

To investigate distinct differentiation patterns in the placenta, we developed a coculture model including three major placental cell types. Aggregates of placental-derived EPCs, CTs and VSCs were generated as described above. Similar techniques have recently been applied to generate spheroid cultures of CT and endothelial cells. ${ }^{40,44}$ The aggregates developed spontaneously in nonadherent culture plates and resulted in stable spheroids. In our model, the placental spheroids revealed significant structural similarities with the differentiation pattern of early placental tissue. Similar to isolated placental villi, differentiation antigens are expressed on CTs, VSCs and EPCs in the new spheroidal model. Cytokeratin-7, a specific marker for CT cells, stains around the spheroidal core and resembles in vivo villous architecture. However, this spheroid model failed to form syncytiotrophoblasts, which could not be detected by immunostaining with NDOG1, a syncytiotrophoblastspecific antibody. In human placenta, syncytiotrophoblasts reveal multinucleated structures resulting from a fusion of mononuclear CTs. ${ }^{8}$ Therefore, extention of the incubation time for spheroid formation may be required in order to detect cytotrophoblastic cell fusions.

It was further demonstrated that spheroids recruited CD $34^{+}$cells similar to the chorionic villous stroma from early placental tissue. Although the utilization of UCB-derived EPCs derived from term placenta may represent a disadvantage of this coculture system, there is no alternative for $\mathrm{CD} 133$ + cells coexpressing the endothelial marker CD34 from UCB at present. ${ }^{45}$ Although addition 

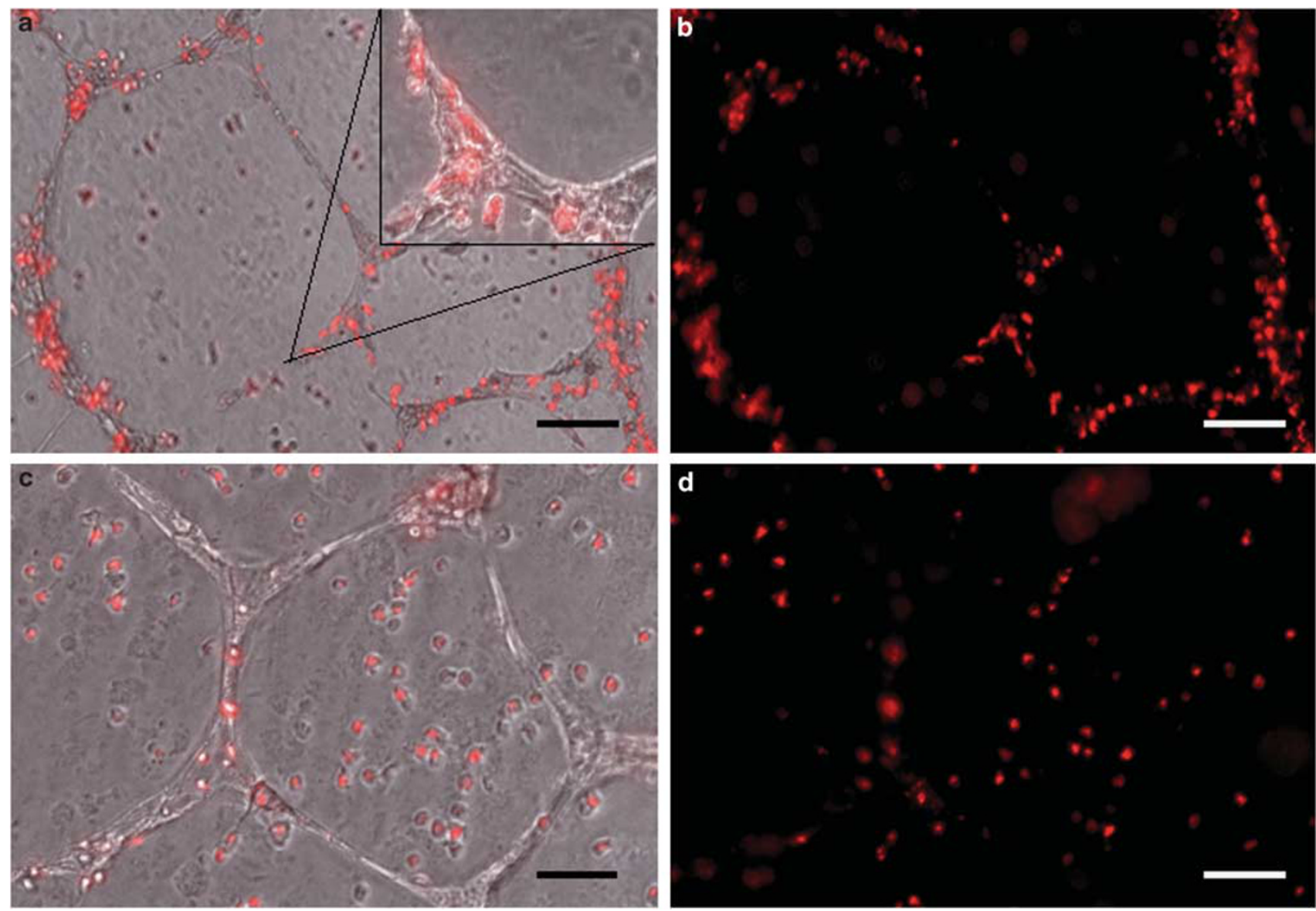

Figure 7 Endothelial cell network formation. Fluorescently labeled EPCs were cultivated in HTR-CM supplemented with $1 \%$ FCS for 4 weeks and subsequently cocultured with HUVECs on growth factor-reduced Matrigel. (a) Phase contrast micrograph overlaid with fluorescent micrograph: EPCs were incorporated into the network formed by HUVEC after $14 \mathrm{~h}$; (b) fluorescent micrograph of incorporated EPCs. (c) Phase contrast micrograph overlaid with fluorescent micrograph: EPCs incubated in IMDM medium supplemented with growth factors and 10\% FCS before cocultivation with HUVECs did not incorporate into the HUVEC network; (d) fluorescent micrograph of not incorporated EPCs. Bars $150 \mu \mathrm{m}$.

of progenitor cells from first trimester placental tissue would be more appropriate, the number of isolated cells would not be sufficient for spheroid generation. Another disadvantage of our model is the inherent difficulty in quantifying antigen expression. To solve this problem in future studies, it may be appropriate to dissociate cellular components from the spheroid and subsequently employ flow cytometry or cell picking methods. Also, it may be of some interest to investigate immunophenotyping after transferring cellular components back to monolayer cultures as recently reported by Potapova et al. ${ }^{46}$

Despite the disadvantages described above, the spheroid model described here offers a whole spectrum of opportunities to study both, physiological as well as pathological events in the early placenta. For example, the spheroid model may be relevant for testing the influence of toxins or viral exposure on vascular development. Recently, a three-dimensional spheroid assay to measure viral-induced oncolysis was successfully established. ${ }^{47}$ The infection of spheroids with different viruses may be used in studies on envelope genes from endogenous retroviruses termed syncytins specifically expressed in the placenta. $^{48}$

Multiple models based on two-dimensional monolayer and explant cultures have been established for analysis of trophoblast differentiation and invasion. ${ }^{49-55}$ Korff et al ${ }^{44}$ successfully developed an invasion assay using a spheroidal CT model to mimic the in vivo phenotype and differentiation of first trimester, third trimester and preeclamptic CT. Our assay combined with the application of the Modular Incubator Chamber allows the investigation of CT invasion and differentiation under low-oxygen environments. CTs leaving the spheroidal core are indicative of the invasive phenotype. These findings are in concert with previously published observations. First trimester CTs intensively invaded the collagen-gel whereas normal and preeclamptic CT cells from third trimester, when maternal blood flow and oxygen supply is fully established, showed a much lower invasive capacity. ${ }^{44}$ In addition, we were able to demonstrate that the expression of SDF-1 $\alpha /$ CXCR4 system crucial for 
migration and adhesion of precursor and stem cells was regulated by oxygen. Our data are in concert with previously published results showing that mRNA- and protein expression of SDF- $1 \alpha$ and CXCR4 is regulated in synovial fibroblasts in a low-oxygen environment. ${ }^{56}$ Furthermore, the recruitment of CXCR4-positive progenitor cells to regenerating ischemic tissues is mediated by hypoxic gradients via HIF-1-induced expression of SDF-1 as showed by Ceradini et al. ${ }^{57}$

As cell-cell interactions are important in differentiation of progenitor and stem cells, our model provides additional insights into these processes during placental vascular development. EPCs grown in human placental trophoblastconditioned medium (HTR-CM) interacted and formed multiple cell spheroids that did not adhere (Figure 6a). They became adhesive, showed an endothelial-like morphology (Figure 6b) and stained with CD68 and VEGFR-3 after the transfer into IMDM medium (Figure $6 \mathrm{c}$ and $\mathrm{d}$ ). We were also able to show that EPCs in HTR-CM were incorporated into capillary networks of endothelial cells (Figure $7 \mathrm{a}-\mathrm{d}$ ).

In conclusion, the three-dimensional spheroid model described in this investigation has proven to be an adequate system for investigations regarding the in vivo situation of placental vasculogenesis and trophoblast invasion. The integration of CTs, VSCs and EPCs into one spheroid, a structure that is morphologically similar to placental villi, will be applicable for future experiments. This spheroid model also allows cultivation of cells in close contact to each other in physiologically relevant low-oxygen environments, further mimicking the in vivo environment.

Supplementary Information accompanies the paper on the Laboratory Investigation website (http://www.laboratoryinvestigation.org)

\section{ACKNOWLEDGEMENTS}

We thank Bettina Gill for technical assistance. The work of our laboratory was supported by a grant from the German Research Council (DFG, Zy 19/32; Zy 19/3-4).

1. Burton GJ, Jauniaux E, Watson A. Maternal arterial connections to the placental intervillous space during the first trimester of human pregnancy: the Boyd collection revisited. Am J Obstet Gynecol 1999;181:718-724.

2. Macara L, Kingdom JCP, Kaufmann P, et al. Structural analysis of placental terminal villi from growth-restricted pregnancies with abnormal umbilical artery Dopplerwaveforms. Placenta 1996;17:37-48.

3. Meekins JW, Pijnenborg R, Hanssens M, et al. A study of placental bed spiral arteries and trophoblast invasion in normal and severe preeclamptic pregnancies. Br J Obstet Gynaecol 1994;101:669-674.

4. Meegdes BH, Ingenhoes R, Peeters LL, et al. Early pregnancy wastage: relationship between chorionic vascularization and embryonic development. Fertil Steril 1988;49:216-220.

5. Barker DJ, Bull AR, Osmond C, et al. Fetal and placental size and risk of hypertension in adult life. BMJ 1990;301:259-262.

6. Zygmunt MT, Herr F, Münstedt $\mathrm{K}$, et al. Angiogenesis and vasculogenesis in pregnancy. Eur J Obstet Gynecol Reprod Biol 2003;110:S10-S18.

7. Kingdom J, Huppertz B, Seaward G, et al. Development of the placental villous tree and its consequences for fetal growth. Eur J Obstet Gynecol Reprod Biol 2000;92:35-43.
8. Charnock-Jones DS, Kaufmann P, Mayhew TM. Aspects of human fetoplacental vasculogenesis and angiogenesis. I. Molecular regulation. Placenta 2004;25:103-113.

9. Cross JC, Werb Z, Fisher SJ. Implantation and the placenta: key pieces of the development puzzle. Science (Wash DC) 1994;266:1508-1518.

10. Fisher SJ, Damsky CH. Human cytotrophoblast invasion. Semin Cell Biol 1993;4:183-188.

11. Zhou Y, Fisher SJ, Janatpour M, et al. Human cytotrophoblasts adopt a vascular phenotype as they differentiate. A strategy for successful endovascular invasion? J Clin Invest 1997;99:2139-2151.

12. Gill KA, Brindle NP. Angiopoietin-2 stimulates migration of endothelial progenitors and their interaction with endothelium. Biochem Biophys Res Commun 2005;336:392-396.

13. Demir $R$, Kaufmann $P$, Castellucci $M$, et al. Fetal vasculogenesis and angiogenesis in human placental villi. Acta Anat (Basel) 1989;136:190-203.

14. Risau W, Flamme I. Vasculogenesis. Annu Rev Cell Dev Biol 1995;11:73-91.

15. Flamme I, Frolich T, Risau W. Molecular mechanisms of vasculogenesis and embryonic angiogenesis. J Cell Physiol 1997;173:206-210.

16. Sato TN, Tozawa $Y$, Deutsch $U$, et al. Distinct roles of the receptor tyrosine kinases Tie-1 and Tie-2 in blood vessel formation. Nature 1995;376:70-74.

17. Suri $C, M c C l a i n ~ J$, Thurston $G$, et al. Increased vascularization in mice overexpressing angiopoietin-1. Science 1998;282:468-471.

18. Hayes AJ, Huang WQ, Mallah J, et al. Angiopoietin-1 and its receptor Tie-2 participate in the regulation of capillary-like tubule formation and survival of endothelial cells. Microvasc Res 1999;58:224-237.

19. Dunk C, Shams M, Nijjar S, et al. Angiopoietin 1 and angiopoietin-2 activate trophoblast Tie-2 to promote growth and migration during placental development. Am J Pathol 2000;156:2185-2199.

20. Jaleel MA, Tsai AC, Sarkar S, et al. Stromal cell-derived factor-1 (SDF-1) signalling regulates human placental trophoblast cell survival. Mol Hum Reprod 2004;10:901-909.

21. Wu X, Li DJ, Yuan MM, et al. The expression of CXCR4/CXCL12 in firsttrimester human trophoblast cells. Biol Reprod 2004;70:1877-1885.

22. Jauniaux $E$, Watson A, Burton $G$. Evaluation of respiratory gases and acid-base gradients in human fetal fluids and uteroplacental tissue between 7 and 16 weeks' gestation. Am J Obstet Gynecol 2001;184:998-1003.

23. McKinnon T. Hematopoietic Stem/Progenitor Cells and Placental Vascular Development: In Vitro Study on the Role of Oxygen and Stromal Derived Factor-1 in the Establishment of a Stem Cell Niche. WB Laufersweiler Verlag: Wettenberg, Germany, 2007.

24. Pauly RR, Passaniti A, Crow M, et al. Experimental models that mimic the differentiation and dedifferentiation of vascular cells. Circulation 1992;86:III.6-III.73.

25. Barnés $C M$, Huang $S$, Kaipainen $A$, et al. Evidence by molecular profiling for a placental origin of infantile hemangioma. Proc Natl Acad Sci USA 2005;102:19097-19102.

26. Kliman HJ, Nestler JE, Sermasi E, et al. Purification, characterization, and in vitro differentiation of cytotrophoblasts from human term placentae. Endocrinology 1986;118:1567-1582.

27. Baal $\mathrm{N}$, Reisinger $\mathrm{K}$, Jahr $\mathrm{H}$, et al. Expression of transcription factor Oct4 and other embryonic genes in CD133 positive cells from human umbilical cord blood. Thromb Haemost 2004;92:767-775.

28. Jaffe EA, Nachman RL, Becker CG, et al. Culture of human endothelial cells derived from umbilical veins. Identification by morphologic and immunologic criteria. J Clin Invest 1973;52:2745-2756.

29. Herr F, Baal N, Reisinger K, et al. HCG in the regulation of placental angiogenesis. Results of an in vitro study. Placenta 2007;28:S85-S93.

30. Liang OD, Korff T, Eckhardt J, et al. Oncodevelopmental alpha-fetoprotein acts as a selective proangiogenic factor on endothelial cell from the fetomaternal unit. J Clin Endocrinol Metab 2004;89:1415-1422.

31. Jauniaux $E$, Watson $A$, Ozturk $O$, et al. In-vivo measurement of intrauterine gases and acid-base values early in human pregnancy. Hum Reprod 1999;14:2901-2904.

32. Librach $\mathrm{CL}$, Werb Z, Fitzgerald ML, et al. 92-kD type IV collagenase mediates invasion of human cytotrophoblasts. J Cell Biol 1991;113:437-449.

33. Delia $D$, Lampugnani MG, Resnati M, et al. CD34 expression is regulated reciprocally with adhesion molecules in vascular endothelial cells in vitro. Blood 1993;81:1001-1008.

34. Wolburg $\mathrm{H}$, Neuhaus $\mathrm{J}$, Kniesel $\mathrm{U}$, et al. Modulation of tight junction structure in blood-brain barrier endothelial cells. Effects of tissue 
culture, second messengers and cocultured astrocytes. J Cell Sci 1994;10:1347-1357.

35. Bates RC, Buret A, van Helden DF, et al. Apoptosis induced by inhibition of intercellular contact. J Cell Biol 1994;125:403-415.

36. Keller GM. In vitro differentiation of embryonic stem cells. Curr Opin Cell Biol 1995;7:862-869.

37. Lincz LF, Buret A, Burns GF. Formation of spheroid structures in a human colon carcinoma cell line involves a complex series of intercellular rearrangements. Differentiation 1997;61:261-274.

38. Müller-Klieser W. Three-dimensional cell cultures: from molecular mechanisms to clinical applications. Am J Physiol 1997;273:C1109-C1123.

39. Sutherland RM. Cell and environment interactions in tumor microregions: the multicell spheroid model. Science 1988;240:177-184.

40. Korff $T$, Augustin HG. Integration of endothelial cells in multicellular spheroids prevents apoptosis and induces differentiation. J Cell Biol 1998;143:1341-1352.

41. Füller $T$, Korff $T$, Kilian A, et al. Forward EphB4 signaling in endothelial cells controls cellular repulsion and segregation from ephrinB2 positive cells. J Cell Sci 2003;116:2461-2470.

42. Korff T, Kimmina S, Martiny-Baron G, et al. Blood vessel maturation in a 3-dimensional spheroidal coculture model: direct contact with smooth muscle cells regulates endothelial cell quiescence and abrogates VEGF responsiveness. FASEB J 2001;15:447-457.

43. Korff $\mathrm{T}$, Augustin HG. Tensional forces in fibrillar extracellular matrices control directional capillary sprouting. J Cell Sci 1999;112:3249-3258.

44. Korff $T$, Krauss T, Augustin HG. Three-dimensional spheroidal culture of cytotrophoblast cells mimics the phenotype and differentiation of cytotrophoblasts from normal and preeclamptic pregnancies. Exp Cell Res 2004;297:415-423.

45. Salven P, Mustjoki S, Alitalo R, et al. VEGFR-3 and CD133 identify a population of $\mathrm{CD}_{3} 4^{+}$lymphatic/vascular endothelial precursor cells. Blood 2003;101:168-172.

46. Potapova IA, Brink PR, Cohen IS, et al. Culturing of human mesenchymal stem cells as 3D-aggregates induces functional expression of CXCR4 that regulates adhesion to endothelial cells. J Biol Chem 2008;283:13100-13107.
47. Lam JT, Hemminki A, Kanerva A, et al. A three-dimensional assay for measurement of viral-induced oncolysis. Cancer Gene Ther 2007:14:421-430.

48. Mangeney M, Renard M, Schlecht-Louf G, et al. Placental syncytins: genetic disjunction between the fusogenic and immunosuppressive activity of retroviral envelope proteins. Proc Natl Acad Sci USA 2007;104:20534-20539.

49. Fisher SJ, Cui TY, Zhang L, et al. Adhesive and degradative properties of human placentalcytotrophoblast cells in vitro. J Cell Biol 1989;109:891-902.

50. Genbacev O, Schubach SA, Miller RK. Villous culture of first trimester human placenta-model to study extravillous trophoblast (EVT) differentiation. Placenta 1992;13:439-461.

51. Burrows TD, King A, Loke YW. Expression of integrins by human trophoblast and differential adhesion to laminin or fibronectin. Hum Reprod 1993;8:475-484.

52. Bischof $P$, Haenggeli $L$, Campana A. Gelatinase and oncofetal fibronectin secretion is dependent on integrin expression on human cytotrophoblasts. Hum Reprod 1995;10:734-742.

53. Caniggia I, Lye SJ, Cross JC. Activin is a local regulator of human cytotrophoblast cell differentiation. Endocrinology 1997;138:3976-3986.

54. Caniggia I, Mostachfi $\mathrm{H}$, Winter J, et al. Hypoxia-inducible factor-1 mediates the biological effects of oxygen on human trophoblast differentiation through TGFbeta(3). J Clin Invest 2000;105:577-587.

55. Malassine A, Frendo JL, Evain-Brion D. A comparison of placental development and endocrine functions between the human and mouse model. Hum Reprod 2003;9:531-539.

56. Hitchon C, Wong K, Ma G, et al. Hypoxia-induced production of stromal cell-derived factor 1 (CXCL12) and vascular endothelial growth factor by synovial fibroblasts. Arthritis Rheum 2002;46: 2587-2597.

57. Ceradini DJ, Kulkarni AR, Callaghan MJ, et al. Progenitor cell trafficking is regulated by hypoxic gradients through HIF-1 induction of SDF-1. Nat Med 2004;10:858-864. 